\title{
Artificial Intelligence Influence In Education 4.0 To Architecture Cloud-Based E-Learning System
}

\author{
P Hendradi ${ }^{a, b, 1}$, Mohd Khanapi Abd Ghani ${ }^{\text {b,2 }}$, S.N Mahfuzah ${ }^{\mathrm{c}, 3}$, Uky Yudatama $^{\mathrm{a}, 4}$, N Agung \\ Prabowo $^{\mathrm{a}, 5}$, R Arri WIdiyanto ${ }^{\mathrm{a}, 6}$ \\ a Teknik Informatika, Universitas Muhammadiyah Magelang, Mayjend Bambang Soegeng KM 5 Mertoyudan, \\ Magelang, 56172, Indonesia, bBiomedical Computing and Engineering Technologies (BIOCORE) Applied Research \\ Group, Faculty of Information and Communication Technology, Universiti Teknikal Malaysia Melaka, Malaysia, \\ cDepartment of Interactive Media, Faculty of Information and Communication Technology, Universiti Teknikal Malaysia \\ Melaka, Malaysia \\ ${ }^{1}$ p_hendra@ummgl.ac.id, , ${ }^{2}$ khanapi@utem.ed, ${ }^{3}$ mahfuzah@utem.edu.my, ${ }^{4} u k y @ u m m g l . a c . i d,{ }^{5}$ n_agung@ummgl.ac.id, \\ ${ }^{6}$ r_arri@ummgl.ac.id
}

ARTICLE INFO

Article history:

Received 20-06-2019

Revised 30-07-2019

Accepted 10-11-2019

Keywords:

Artificial Intelligent

E-Learning

Education 4.0

\section{ABSTRACT}

Business Application Layer in the Architecture of E-learning cloud is an essential part since it is the section that differentiates from the cloud in other fields. The development of learning today recognizes the term Education 4.0, which is an adaptation of the Industrial era and vital in Artificial Intelligence. This paper review a part of the cloud-based architecture of E-Learning, which corresponds to Education 4.0. It aims to produce a Cloud-Based E-learning system Architecture design used as a guideline in the direction of Education 4.0.

Copyright () 2017 International Journal of Artificial Intelligence Research All rights reserved.

\section{Introduction}

The cloud-based e-learning system is an evolution of the previously web-based program, often referred to as traditional e-learning [1]. Implementation of cloud computing in e-learning systems increase usability, and this is vital in the digital era. The use of Cloud means that the e-learning system resources are not adequately provided by the institution, but are instead availed by third parties/cloud service provider. This also creates a new opportunity in its development, namely the existence of e-learning cloud business models [2]. However, due to the variety of capabilities of the institutions in implementing cloud-based e-learning systems, the elastic cloud computing model also appears elastically applied.

Moreover, there is also the adoption of the Industrial era and education 4.0, which is an evolution of learning in parallel to the Industry. This is because Education 4.0 requires a strong partnership between industry and the academic environment in the creating of human resources [3]. The significance of Education 4.0 compared to the previous systems involve features driven by Artificial Intelligence (AI). Essentially, Industry 4.0 also has two of the three trends besides AI, including Transparent Immersive Experiences and Digital Platforms, which affect daily life.

Cloud-based e-learning and Education 4.0 meet the evolution of web 4.0 in case they are drawn in time-line [6]. However, there is no discussion about the link between Education 4.0 and the Cloud-Based E-learning system. The influence of AI in the application changes the paradigm in business processes, as well as in e-learning systems [7].

This paper presents the relationship between cloud-based e-learning architecture in education 4.0 by reviewing the e-learning system architecture. It aims to produce a Cloud-Based E-learning system Architecture design to be used as a guideline in the direction of Education 4.0. Additionally, it is meant to provide stakeholders guidance in cloud-based e-learning systems in improving their services. 


\section{Research Methodology}

This is a literature review with findings based on an evaluation and analysis of the works related to cloud-based e-learning architecture in education 4.0. It is effected by reviewing the architecture of e-learning systems and educational features. Therefore a systematic review is carried out in several steps including, formulating the review questions, devising the search strategies, study selection criteria, quality assessment and design of the studies [8].

\section{A. Formulate the research question}

The formulation of the review questions based on identifying the focus and boundaries, as well as forming aspects of the review process, such as inclusion and exclusion criteria, search strategies, the extent of literature reviewed, quality assessment, and synthesis of evidence. The research question is: "How does Artificial Intelligence in Education 4.0 influence the architecture of cloudbased e-learning systems?"

\section{B. Devising the search strategy}

Devising the search strategy is conducted comprehensively using Google and Google Scholar. The keywords used to quote from the theme of this paper, which is "architecture cloud base elearning system" and "Artificial Intelligent + Education 4.0". From these articles, a review of the use of the keywords was carried out.

In the article with the theme "architecture cloud base e-learning system," the keywords used include architecture, cloud computing, e-learning, and information technology. In contrast, the article "Artificial Intelligent + Education 4.0," the keywords used include education 4.0, learning analytics, machine learning, industry 4.0 , and artificial intelligence. By considering the criteria and strategies to obtain the appropriate reference, then four keywords are chosen, including e-learning, cloud computing, education 4.0, and artificially intelligent.

\section{Study selection criteria}

The study used first is a series of inclusion criteria, and the second is a series of exclusion criteria related to the review question. The following is a table of proposed criteria, literature by year and literature by keyword

Table 1 Literature Review Selection Criteria

\begin{tabular}{cc}
\hline Inclusion Criteria & Exclusion Criteria \\
\hline Paper Published between 2014 to 2018 & Paper Published between less than 2014 to \\
2018 \\
The paper addresses the E-Learning System & The paper addresses Artificial Intelligent, \\
Cloud Computing \\
Papers focus on e-learning, Cloud, Education 4.0 & $\begin{array}{c}\text { paper containing Artificial Intelligence and } \\
\text { cloud computing in general }\end{array}$ \\
\hline
\end{tabular}

Table 2 Literature by year

\begin{tabular}{cc}
\hline Year & paper \\
\hline 2018 & 5 \\
2017 & 10 \\
2016 & 2 \\
2015 & 2 \\
$<2014$ & 5 \\
\hline
\end{tabular}

\section{Quality appraisal criteria}

The keywords used include E-learning, Cloud Computing, Education 4.0, and Artificial Intelligent between 2015 and 2018. After an in-depth reading and review based on the specified criteria selected, 24 works of literature were obtained. The criteria need to be relevant and support 
the aim of the research, and the journal reputation is indexed by Scopus. The results are presented in Table 3.

Table 3 Literature by keyword

\begin{tabular}{cc} 
Keyword & paper \\
\hline E-Learning & 5 \\
Cloud Comp & 10 \\
Education 4.0 & 6 \\
Artificial Intelligent & 3 \\
\hline
\end{tabular}

\section{E. Design of the studies}

This study only included empirical evidence from various experimental or observational studies, which involved qualitative and quantitative research. Furthermore, the research is highly related to the Influence of AI on Education 4.0 in the Cloud-based E-learning system.

Based on the table, the first part of the paper is an introduction, which contains background and research methods, while the second involves the related work with a review of the works by the keywords in the search. The third part deals with the influence of AI in each keyword, while the fourth involves a discussion and proposal of the system architecture and the influence of AI. The last part is the conclusion and future work of this research.

\section{Related Work}

\section{A. Cloud-based E-learning}

Cloud computing based on the e-learning system is a continuation of the previous generation program, referred to as web-based e-learning, though it is perceived as traditional [9]. The fundamental difference between the two is the resource management, wherein traditional e-learning, resources are provided by institutions or internally, but in cloud-based e-learning, third parties emerge as providers of the necessities [2].

Cloud-based E-learning Architecture might be divided into five main layers, including Hardware Resource, Software Resource, Resource Management, Service, and Business Application (Riahi 2015; Laisheng and Zhengxia 2011). In research on the elasticity of cloud computing from the five layers, the infrastructure part is the most influential [10].

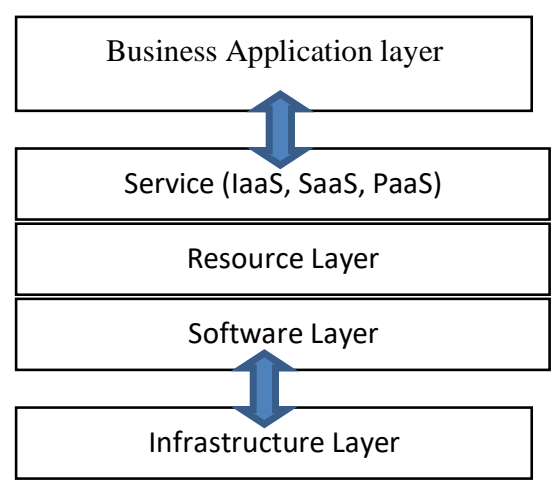

Fig. 1.E-Learning Cloud Architecture

According to the discussion of business paradigms in cloud-based e-learning, there are three essential elements, including cloud provider, e-learning cloud and cloud user, each with a relationship as shown below [2]: 


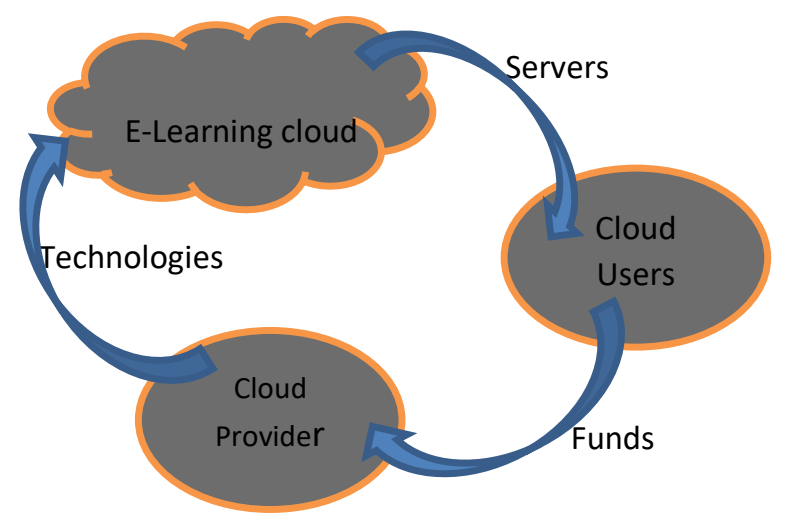

Fig. 2. The business model of E-Learning Cloud

From the diagram, the role of the provider is to develop and maintain an e-learning cloud. Importantly, Cloud Users pay providers for their services based on the usage.

Of the five layers highlighted earlier, Business Application is the main key distinguishing cloudbased systems from one another. In this context, there are three more sub-layers, including Infrastructure, Content, and Application [1]. Some divide it into five, including delivery, education platforms content creation, content, teaching evaluation, and education management [2]. They may also be divided into six parts, Content Production, Delivery Content, Collaboration, Virtualization, Assessment, and Management [9].

\section{B. Typical architecture of the cloud-based e-learning systems}

Cloud-based e-learning systems often take consider the demands of educational institutions such as resource virtualization, centralized data storage, low operational costs, scalability, flexibility, and availability of e-learning systems. Therefore, cloud-based e-learning architecture mostly uses the elearning approach in the Cloud [11]. It includes a cloud management system, all hardware, and software computing resources and services offered by the Cloud [12].

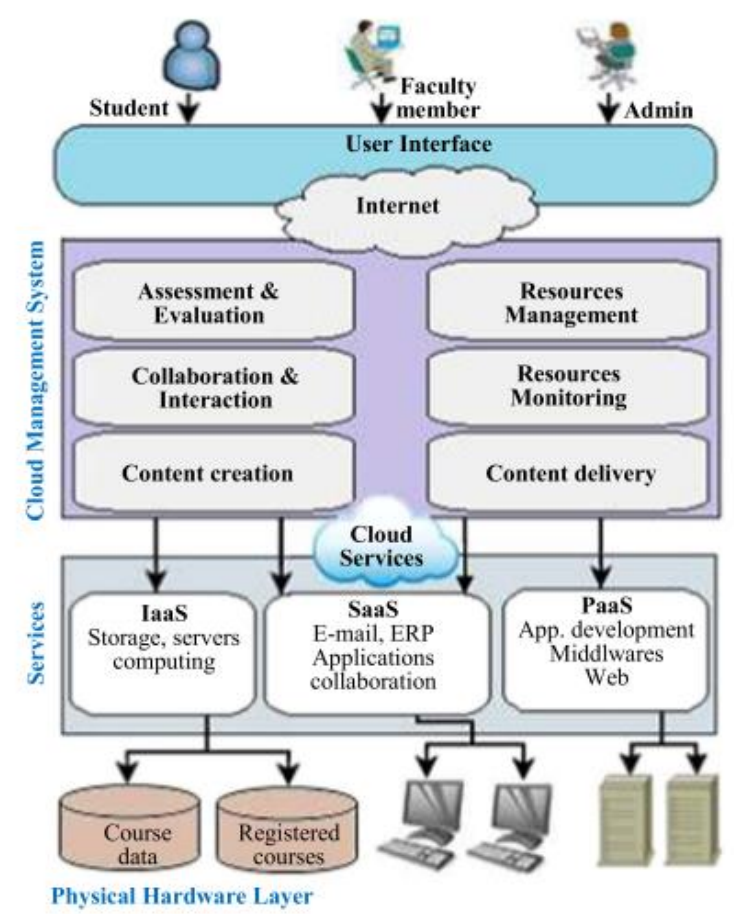

Fig. 3.Common architecture of the cloud-based e-learning system 


\section{Education 4.0}

The term Education 4.0 refers to an adaptation of the Industrial Age 4.0 revolution, which addresses several aspects supported by computer technology, the Internet of Things, the Internet of Services, and the Internet of People. [13]. It is meant to address the needs of the industry by sharpening Artificial Intelligent (AI) features with emphasis on seven aspects [3]. These include; (1) The material prepared for different learning types, such as interactive book and video or in other words personalization; (2) Playful and virtual-reality elements often referred to as gamification; (3) The practice mobile connectivity, where students use their own devices to access and interact with the system. Currently it is possible to do this since the data shows the penetration of smartphone devices and internet access is increasing [14]; (4) The course modules adapt themselves, meaning each student have a different track according to background and behavior (adaptability); (5) Learning Analytics-method where the system has the ability to track and provide support programs; (6) Intelligent teletutors or the Chabot application, which is a robot chat application as if students interact with the tutor; (7) E-Assessments - the teacher do an assessment and correction automatically.

In the Education profile, there are six attributes, including Teacher, Submission of Content, Learning Process, Learning Organization, Students, and Facilities [15]. These six attributes form the basis of the development of each period, such as the Education 1.0, Education 2.0 to Education 4.0. For instance, Teacher Education 4.0 profile is the development of Education 3.0, where the tutor is the leader of collaborative knowledge creation coupled with support from the AI-based e-learning portal (Teacher Education 3.0 $+\mathrm{AI}=$ Teacher Education 4.0). All profiles are added based on the AI system, as shown below:

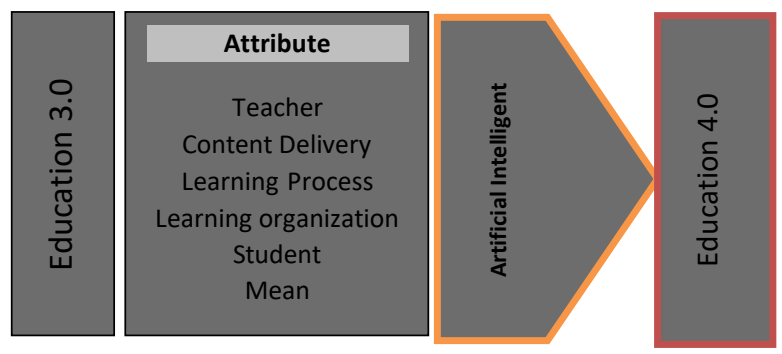

Fig. 4.Evolution Education 3.0 to Education 4.0

\section{Artificial Intelligent in Cloud Computing}

Artificial intelligence (AI) reproduces the results of the analysis of intelligence and behavior based on assumptions. In this context, reproduction means simulation by a computer [16]. The presence of AI is meant to improve cloud technology. It might also be the opposite; cloud technology may provide the information needed for the learning process and help Cloud by offering more data [17].

AI and Cloud Computing are changing massively in the corporate world, and their fusion referred to as the technology to come [17]. The figure below shows an example of the presence of $\mathrm{AI}$ in Cloud Computing:

Infrastructure as a Service (IaaS) facilitates the presence of AI, such as elastic cloud computing [10]. It is an architecture that matches the number of resources allocated to service with the actual needs. For this reason, a load balancer, PHP servers, and MySQL server are used.

At Platform as a Service (PaaS), AI acts as an acceleration in the form of a chain of relationships between ecosystem-Customer platforms [7]. 


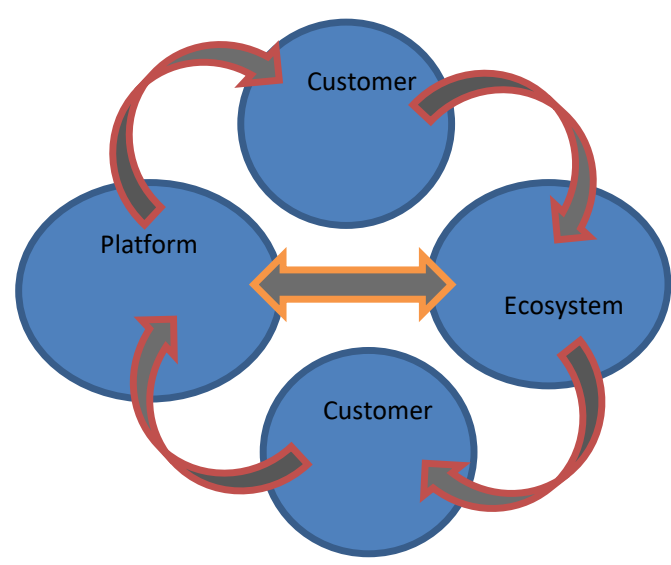

Fig. 5.Platform Ecosystem

In the figure 5, the relationship chain becomes an ecosystem influences the development of the platform described as a business model pipe, such as the Oracle AI Cloud Service Platform [18].

Software as a Service (SaaS) is a delivery model allowing the use of programs provided by third parties using the internet network [19]. In SaaS system architecture, Artificial Intelligent is in the form of Machine Learning (ML), which is a component involved in Machine-To-Human (M2H) workflows [20]. Machine Learning Cluster runs a fundamental recommendation algorithm in the M2H workflow.

Besides, SaaS is also taking the trend for AI and ML, including in personalization, automation, deploying code, predictive analytics, and enhanced security [21]. For instance, the presence of AI in SaaS is in the form of hyper-personalization, which is a customized content for users as a result of collaboration with Machine Learning.

\section{E. Relation Education 4.0 to Cloud based e-learning}

The relationship of five attributes of Education 4.0 and the Business Application Layer of the cloud-based e-learning system architecture is based on the three layers, including application, content, and infrastructure [1]. All these adapt from the Table Relation E-learning Cloud Layer [22]. In case it is combined with the Cloud E-learning architecture, layers are connected to the Cloud Management System, and both the Business Application and the Resource are accessed later.

\section{Analyst}

From the cloud-based e-learning system architecture consisting of five layers, the role of AI is explained only in two of them, Service and Business Application. In the Service Layer, the role of $\mathrm{AI}$ is evident, and each service in the Cloud adopts it to develop its service. In the Infrastructure as a Service (IaaS), the presence of AI is in the form of elastic cloud computing [10]. On Platform as a Service (PaaS), AI is a chain of relationships between customer-ecosystem platforms acting as an acceleration [7], while Software as a Service (SaaS) is a delivery model [19]. In the Business Application Layer, the role of AI is obtained by connecting to attribute Education 4.0 [15].

As for the Business Application and Resource Layers, the role of AI is developed by referring to the relationship between Education 4.0 and Cloud-based e-learning. Therefore, to explain the influences of AI, a six-part cloud management system is used by correlating it to Education 4.0. 
Table 4 AI Influence in Architecture Cloud base E-learning

\begin{tabular}{|c|c|c|}
\hline $\begin{array}{c}\text { Six-part cloud management } \\
\text { system [2] }\end{array}$ & AI Influence & $\begin{array}{c}\text { Education } \\
4.0 \\
\end{array}$ \\
\hline Assessment \& Evaluation & $\begin{array}{l}\text { The artificial intelligence-based assessment provides constant } \\
\text { feedback to teachers, students and parents on how the student } \\
\text { learns, the support they need and the progress they are making } \\
\text { towards their learning goals [23] }\end{array}$ & $\begin{array}{l}\text { The } 7 \text { Facets } \\
\text { Of Education } \\
4.0\end{array}$ \\
\hline Collaboration \& Interaction & $\begin{array}{l}\text { AI provides the device which reacts and responds to commands. } \\
\text { Soon voice recognition might be faster than typing. (Ciolacu et } \\
\text { al. 2018) }\end{array}$ & $\begin{array}{l}\text { The } 7 \text { Facets } \\
\text { Of Education } \\
\quad 4.0\end{array}$ \\
\hline Content creation & $\begin{array}{l}\text { The contents created in this platform are computable, providing } \\
\text { the learner the capability to easily change the environment and } \\
\text { repeat the computable task as many times as needed. The } \\
\text { contents are scalable, and the students learn, practice, and } \\
\text { gradually deepen their knowledge step by step [24]. }\end{array}$ & N/A \\
\hline Resource Management & $\begin{array}{l}\text { A student is autonomous, and counselors and AI help co- } \\
\text { develop education plans, continuously updated by adaptive } \\
\text { mechanisms[3] }\end{array}$ & $\begin{array}{l}\text { The Feature of } \\
\text { Education } 4.0\end{array}$ \\
\hline Resource Monitoring & $\begin{array}{l}\text { Resource monitoring, for example, the system providing } \\
\text { material for each type of learning is different since not every } \\
\text { student gets the same virtual material. (Ciolacu et al. 2018). }\end{array}$ & $\begin{array}{l}\text { The } 7 \text { Facets } \\
\text { Of Education } \\
4.0\end{array}$ \\
\hline Content delivery & $\begin{array}{l}\text { The availability of AI-based learning portals integrates certified } \\
\text { Open Educational Resources with individual adaptive } \\
\text { learning[15] }\end{array}$ & $\begin{array}{c}\text { Education } 4.0 \\
\text { Attribute }\end{array}$ \\
\hline
\end{tabular}

\section{Result}

In the Cloud-based E-learning system architecture, the program enters the Education 4.0 era by adding AI, which is parallel to the Industry 4.0. The influence of the AI described is in three layers, including Service, Resource, and Business Application.

In-Service Layer, there are three models from the cloud provider and the presence of AI makes each service dynamic and include the Education 4.0 era. Among the three cloud services, Software As a Service (SaaS) is vital in the AI on Education 4.0.

In the Business Application Layer, AI has a dominant role. Connecting Attributes from profile Education 4.0 with layers in the Business Application is complete.

Figure 6 shows the proposed cloud-based E-learning System architecture with three layers, including Service, Resource, and Business Application.

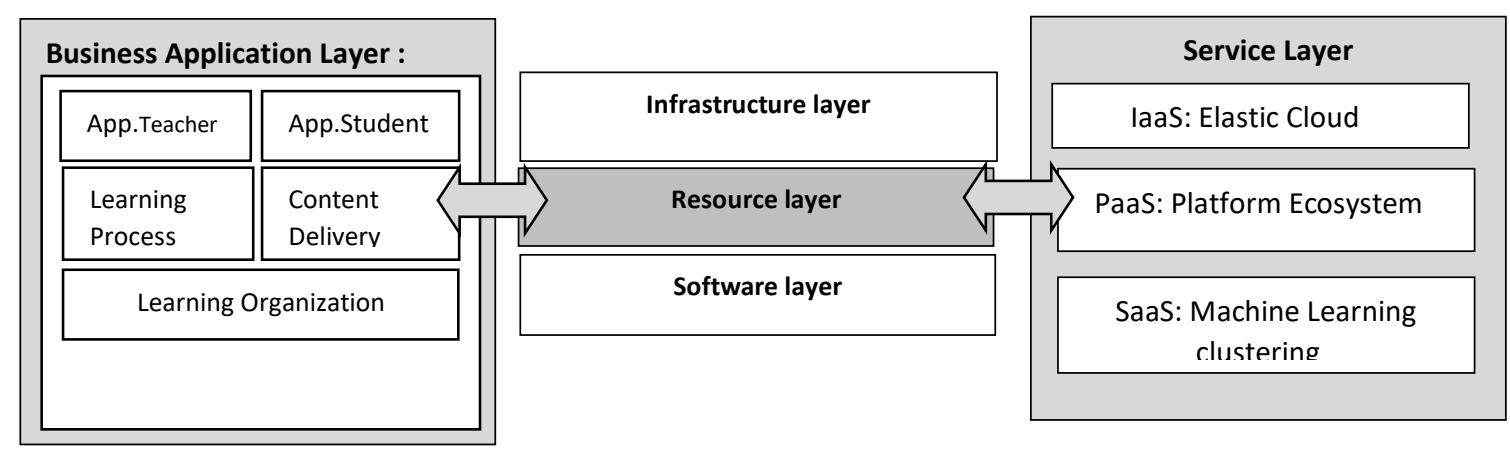

Fig. 6.Propose Architecture Cloud-based E-learning system in Education 4.0

\section{Conclusion}

Artificial Intelligent Influence in the cloud-based e-learning system architecture is evident in the three layers, including service, resource, and business application. The service Layer is a portion of the third party offering facilities as a cloud service provider. In the resource Layer, AI work at student interact section, while in the business application, it makes changes to the behavior of 
teachers and students and influence the supporting facilities, such as learning processes and organizations, and content delivery.

\section{Acknowledgments}

This report is a section chapter 2 of the author's Ph.D. dissertation program at the Fakulti Teknologi Maklumat dan Komunikasi (FTMK) at the Universiti Teknikal Malaysia Melaka (UTeM) with the primary supervisor Prof. Dr. Khanapi Bin Abd Ghani and co-supervisor Dr. Siti Nurul Mahfuzah Mohamad .

\section{References}

[1] G. Riahi, "E-Learning Systems Based on Cloud Computing: A Review," Procedia Comput. Sci., vol. 62, no. Scse, pp. 352-59.

[2] X. Laisheng and W. Zhengxia, "Cloud Computing: A New Business Paradigm for E-Learning," in Tirth International Conference on Meansuring Technology and Mechatronic Automation.

[3] M. Ciolacu, P. M. Svasta, W. Berg, and H. Popp, "Education 4.0 for Tall Thin Engineer in a Data Driven Society," in 2017 IEEE 23rd International Symposium for Design and Technology in Electronic Packaging, SIITME 2017 - Proceedings 2018-Janua, pp. 432-37.

[4] “Three Megatrends That Will Drive Digital Business Into the Next Decade Cycle, Gartner,No Title.”.

[5] M. Ciolacu, A. F. Tehrani, R. Beer, and H. Popp, "Education 4 . 0 - Fostering Student' s Performance with Machine Learning Methods," in International Symposium for Design and Technology in Electronic Packaging, pp. 438-43.

[6] F. A. Alghamdi, “An Integrated Cloud Model for Intelligent E-Learning System,” vol. 13, no. 14. pp. 11484-90.

[7] K. Lee, "AI Platform to Accelerate API Economy and Ecosystem,” Harv. Bus. Rev., pp. 848-52.

[8] B. Kitchenham, O. P. Brereton, D. Budgen, M. Turner, J. Bailey, and S. Linkman, "Systematic literature reviews in software engineering - A systematic literature review," Inf. Softw. Technol., vol. 51, no. 1, pp. 7-15, 2009, doi: 10.1016/j.infsof.2008.09.009.

[9] H. Masud and X. Huang, “An E-Learning System Architecture Based on Cloud Computing.” pp. 74-78.

[10] T. Education, "A New E-Learning Model Based on Elastic Cloud Computing for Distance Education," EURASIA J. Math. Sci. Technol. Educ., vol. 8223, no. 12, pp. 8393-8403.

[11] A. Fernández, D. Peralta, F. Herrera, and J. M. Benítez, "An Overview of E-Learning in Cloud Computing," in Advances in Intelligent Systems and Computing 173 AISC, pp. 35-46.

[12] E. Mhouti, M. E. Abderrahim, and A. Nasseh, "Using Cloud Computing Services in E-Learning Process: Benefits and Challenges," Educ. Inf. Technol., vol. 23, no. 2, pp. 893-909.

[13] M. Hermann, T. Pentek, and B. Otto, "Design Principles for Industrie 4 . 0 Scenarios," in 2016 49th Hawaii International Conference on System Sciences, pp. 3927-36.

[14] APJII, "Penetrasi \& perilaku pengguna internet indonesia," 2017. .

[15] C. Demartini and P. Torino, "Do Web 4.0 and Industry 4.0 Imply Education X.0," IEEE Comput. Soc. (June, pp. $4-7$.

[16] A. Garnham, Artificial Intelligence. London and New York: Routledge \& Kegan Paul.

[17] I. Technologies, "How Artificial Intelligence Is Transforming Cloud Computing," in 2016 49th Hawaii International Conference on System Sciences (HICSS, pp. 848-52.

[18] M. W. V. Alstyne, G. G. Parker, and S. P. Choudary, "Pelines, Platforms , and the New Rules of Strategy." .

[19] D. Mishra and S. Shekhar, "Artificial Intelligence Candidate Recruitment System Using Software as a Service ( SaaS ) Architecture,” Int. Res. J. Eng. Technol., vol. 5, no. 5, pp. 3804-8.

[20] A. Galletta, L. Carnevale, A. Celesti, M. Fazio, and M. Villari, "A Cloud-Based System for Improving Retention Marketing Loyalty Programs in Industry 4.0: A Study on Big Data Storage Implications,” IEEE Access, vol. 6, no. c, pp. 5485-5492, 2017, doi: 10.1109/ACCESS.2017.2776400.

[21] J. Tarud, "How SaaS Can Use AI and Machine Learning." .

[22] P. Hendradi, M. Khanapi, and S. N. Mahfuzah, "Cloud Computing-Based e-Learning System Architecture in Education 4.0,” J. Phys. Conf. Ser., vol. 1196, no. 1, pp. 0-7. 
[23] R. Luckin, "Towards Artificial Intelligence- Based Assessment Systems.”.

[24] P. Rad and N. Beebe, "AI Thinking for Cloud Education Platform with Personalized Learning 3 . Computational Thinking : Definitions,” vol. 9, pp. 3-12, 2018. 